\title{
KLASIFIKASI TINGKAT DEHIDRASI BERDASARKAN KONDISI URINE, DENYUT JANTUNG DAN LAJU PERNAPASAN
}

\author{
Rizal Maulana*1, Muhammad Rheza Caesardi², Eko Setiawan ${ }^{3}$ \\ 1,2,3 Teknik Komputer, Fakultas Ilmu Komputer, Universitas Brawijaya \\ Email: 1rizal_lana@ub.ac.id, ${ }^{2}$ rhezacaesardi@student.ub.ac.id, ${ }^{3}$ ekosetiawan@ub.ac.id \\ *Penulis Korespondensi
}

(Naskah masuk: 19 November 2020, diterima untuk diterbitkan: 22 Maret 2021)

\begin{abstract}
Abstrak
Dehidrasi merupakan suatu kondisi ketika tubuh kekurangan cairan. Secara umum terdapat tiga tingkatan dehidrasi, yaitu dehidrasi ringan, sedang dan berat. Tingkatan dehidrasi berat sangat berbahaya bagi penderitanya, bahkan dapat mengakibatkan kematian. Untuk mencegah terjadinya tingkatan dehidrasi yang berbahaya, maka diperlukan pendeteksian secara dini agar penderita dehidrasi segera mendapatkan penanganan yang cepat dan tepat. Terdapat beberapa parameter yang dapat digunakan untuk mendeteksi dehidrasi, diantaranya warna dan kadar ammonia pada urine, denyut jantung dan laju pernapasan. Pada penelitian ini, dirancang sebuah sistem klasifikasi tingkatan dehidrasi berdasarkan empat parameter tersebut dengan menggunakan metode klasifikasi $k$ nearest neighbor. Sistem yang dirancang mampu memberikan kemudahan untuk melakukan pemeriksaan secara mandiri dan mendapatkan hasil klasifikasi tingkat dehidrasi secara real-time. Dataset yang digunakan dalam penelitian ini berjumlah 75 data yang didapatkan dari pasien diare yang menjalani perawatan di Rumah Sakit. Data tersebut sudah memiliki tingkatan dehidrasi berdasarkan diagnosis dari dokter. Dari hasil pengujian yang telah dilakukan, metode $k$-nearest neighbor memiliki tingkat akurasi terbaik pada penggunaan nilai $\mathrm{k}=5 \mathrm{dan} \mathrm{k}=7 \mathrm{dengan}$ nilai akurasi sebesar $96 \%$.
\end{abstract}

Kata kunci: dehidrasi, urine, denyut jantung, laju pernapasan, klasifikasi, k-nearest neighbor

\section{CLASSIFICATION OF DEHYDRATION LEVELS BY URINE CONDITION, HEART RATE AND RESPIRATORY RATE}

\begin{abstract}
Dehydration is a condition when the body lacks of fluids, caused by the amount of fluid released by the body is greater than the fluids that enters the body. Dehydration is divided into three levels, mild, moderate and severe. Severe dehydration is very dangerous and can even lead to death in patients. To prevent dangerous levels of dehydration, early detection is needed to provide fast and precise treatment to patients. There are several parameters that can be used to detect dehydration, such as color and ammonia levels in urine, heart rate and respiratory rate. This paper designed a system to classify dehydration levels based on these four parameters using $k$-nearest neighbor classification method. The system is designed to be easy to use independently and provides real-time classification results. There are 75 datasets used in this paper, obtained from diarrhea patients in a hospital in Malang. Each data already has a label in the form of dehydration level based on the doctor's diagnosis. From the test result, $k$-nearest neighbor has the best classification accuracy at $k=5$ and $k=7$ with the accuracy of $96 \%$.
\end{abstract}

Keywords: dehydration, urine, heart rate, respiratory rate, classification, $k$-nearest neighbor

\section{PENDAHULUAN}

Teknologi perangkat pintar dalam bidang medis merupakan salah satu teknologi yang dapat digunakan untuk mendeteksi gejala dari suatu penyakit secara dini. Pendeteksian secara dini diperlukan untuk mencegah berkembangnya penyakit menjadi tingkat yang lebih berbahaya. Salah satu jenis penyakit yang perlu dideteksi secara dini adalah dehidrasi. Dehidrasi merupakan kondisi dimana tubuh kekurangan cairan. Hal ini terjadi karena cairan yang dikeluarkan oleh tubuh melebihi cairan yang masuk (Shaheen et al., 2018). Terdapat beberapa penyebab berkurangnya cairan dalam tubuh, seperti keringat yang berlebih dan luka bakar. Selain itu, gangguan pada saluran pencernaan seperti muntah dan diare juga dapat menyebabkan tubuh kekurangan cairan (Andrews et al., 2017). Secara umum, 
dehidrasi terbagi menjadi tiga tingkatan, yaitu dehidrasi ringan, sedang dan berat. Dehidrasi ringan terjadi ketika tubuh kehilangan 3-5\% cairan, dehidrasi sedang ketika tubuh kehilangan 5-10\% cairan dan dehidrasi berat ketika tubuh kehilangan lebih dari 10\% cairan (Fukushima et al., 2018). Karena sebagian besar kandungan tubuh manusia adalah air, maka ketika kandungan air berkurang akan menyebabkan ketidakseimbangan fungsi organ-organ di dalam tubuh. Bahkan pada tingkatan dehidrasi berat dapat menyebabkan kematian penderitanya.

Gejala dehidrasi dapat dilihat dari beberapa tanda klinis, diantaranya rasa haus, kondisi urine, denyut jantung maupun laju pernapasan (Koleva, 2019). Kondisi urine dalam tubuh dapat memberikan informasi mengenai tingkat kejernihan, warna maupun bau. Urine memiliki tingkatan warna yang berbeda sesuai dengan tingkat konsumsi air yang masuk ke dalam tubuh. Konsumsi cairan yang cukup menyebabkan warna urine bening dan cerah, sedangkan kurangnya konsumsi cairan menyebabkan warna urine menjadi pekat (Gunawan et al., 2018). Adapun bau urine dipengaruhi oleh kandungan ammonia yang ada di dalam tubuh. Dimana kadar ammonia dalam urine berbanding terbalik dengan jumlah konsumsi cairan (Willihnganz, Gurevitz \& Clayton, 2020). Gejala dehidrasi juga dapat diketahui melalui denyut jantung. Berkurangnya cairan dalam tubuh secara langsung menyebabkan berkurangnya volume darah. Untuk mengatasi hal tersebut, maka jantung akan memompa darah lebih cepat dibandingkan keadaan normal. Sehingga denyut jantung pada penderita dehidrasi akan meningkat (Severeyn et al., 2016). Selain meningkatknya denyut jantung, penderita dehidrasi juga akan mengalami peningkatan laju pernapasan. Tanpa adanya cairan yang memadai, tubuh tidak dapat memberikan energi yang cukup bagi sel untuk dapat bekerja. Oleh karena itu, peningkatan laju pernapasan diperlukan untuk mengkompensasi permasalahan tersebut agar sel tetap dapat bekerja (Kim \& Kwak, 2019).

Penelitian mengenai pendeteksian dan klasifikasi tingkat dehidrasi telah dilakukan oleh penulis. Pada penelitian sebelumnya, klasifikasi tingkat dehidrasi dilakukan dengan hanya menggunakan parameter warna dan kadar ammonia dalam urine. Nilai kedua parameter tersebut diproses menggunakan metode Naive Bayes untuk dapat diklasifikasikan dalam tingkatan dehidrasi ringan, sedang dan berat. Dari hasil pengujian yang telah dilakukan, sistem ini memiliki akurasi sebesar 95,45\% (Maulana, Syauqy \& Amani, 2017). Untuk meningkatkan nilai akurasi sistem, maka pada penelitian lanjutan ini akan menambahkan parameter denyut jantung dan laju pernapasan. Pada penelitian ini, nilai RGB dari warna urine dideteksi menggunakan sensor warna TCS3200. Nilai dari kandungan gas ammonia dideteksi menggunakan sensor gas MQ135. Jumlah denyut jantung dideteksi menggunakan sensor MAX30100. Sedangkan untuk laju pernapasan diukur menggunakan sensor flex.

Berbeda dengan penelitian sebelumnya yang menggunakan metode Naive Bayes, proses klasifikasi pada penelitian ini menggunakan metode k-nearest neighbor (KNN). Salah satu kelebihan dari metode KNN adalah tahan terhadap data latih yang memiliki derau. Metode ini pernah digunakan oleh Balamurugan dalam mendiagnosis penyakit Alzheimer. Pada penelitian tersebut, metode KNN memiliki akurasi sebesar 99\% dalam mengklasifikasikan kondisi normal, Mild Cognitive Impairment (MCI) atau kerusakan kognitif ringan dan kondisi Alzheimer (Balamurugan, Nancy \& Vijaykumar, 2017). Pada penelitian yang kami lakukan, metode KNN akan diimplementasikan untuk mengklasifikasikan tingkatan dehidrasi ringan, sedang dan berat berdasarkan parameter warna dan kadar ammonia pada urine, denyut jantung dan laju pernapasan.

\section{METODE PENELITIAN}

Tujuan dari penelitian ini adalah untuk merancang dan mengimplementasikan sebuah sistem yang mampu untuk mendeteksi secara dini tingkatan dehidrasi ringan, sedang dan berat. Pengklasifikasian ditentukan berdasarkan parameter warna dan kadar ammonia urine, denyut jantung dan volume pernapasan. Pengklasifikasian ini diproses menggunakan metode KNN yang dilakukan di dalam mikrokontroller. Hasil klasifikasi yang didapatkan kemudian ditampilkan pada sebuah LCD. Diagram blok sistem secara keseluruhan ditunjukkan pada Gambar 1.

\subsection{Pendeteksian Warna Urine}

Warna urine pada penelitian ini dideteksi menggunakan modul sensor warna TCS3200. Modul sensor ini terdiri dari empat buah LED dan sebuah matriks fotodioda berukuran $8 \times 8$ piksel. Dimana matriks fotodioda tersebut mempunyai 16 filter warna merah, 16 filter warna hijau, 16 filter warna biru dan 16 fotodioda tanpa filter. Masing-masing filter disusun secara berselingan dan terhubung secara paralel dalam matriks tersebut. Keluaran dari fotodioda berupa arus yang besarnya sebanding

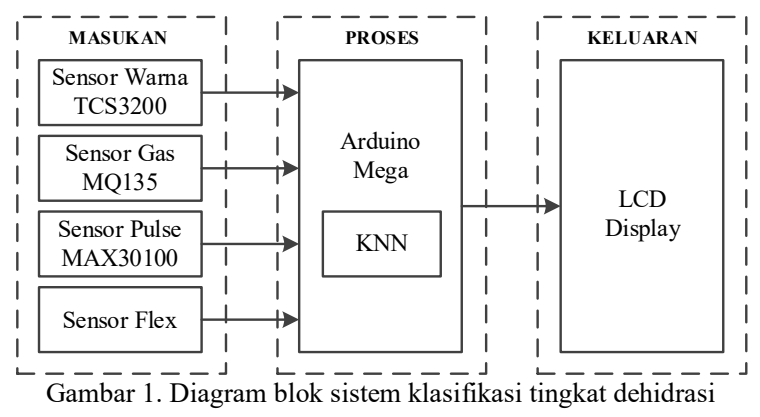


dengan kadar warna dasar cahaya yang dideteksi. Arus keluaran fotodioda kemudian dikonversikan menjadi sinyal kotak oleh sebuah oscillator yang terdapat pada modul sensor tersebut, dengan frekuensi keluaran oscillator sebanding dengan besarnya arus keluaran fotodioda. Untuk mendapatkan nilai RGB dari warna yang dideteksi oleh sensor, maka diperlukan sebuah program penghitung frekuensi keluaran oscillator (Panie \& Mutiara, 2018).

Perancangan perangkat keras dalam penelitian ini ditunjukkan pada Gambar 2. Pada gambar tersebut dapat diketahui bahwa sampel urine yang akan dideteksi warna dan kadar ammonianya diletakkan pada sebuah botol kecil yang dimasukkan di dalam sebuah boks. Sensor warna diletakkan tepat di bawah botol urine tersebut. Botol urine yang digunakan berwarna bening, untuk memudahkan sensor warna dalam mendeteksi warna urine yang diujikan. Penempatan botol urine dan sensor warna di dalam boks bertujuan untuk mengurangi interferensi cahaya dari luar yang dapat mengakibatkan kesalahan pembacaan warna urine. Dimana dalam penelitian ini digunakan boks berwarna hitam, agar tidak terdapat cahaya yang masuk ke dalam boks. Terdapat tiga nilai yang didapatkan dari pembacaan sensor TCS3200 ini, yaitu nilai $R, G$ dan $B$ dari warna urine.

\subsection{Pendeteksian Kadar Ammonia Pada Urine}

Sensor yang digunakan untuk mendeteksi kadar ammonia pada urine dalam penelitian ini adalah MQ135. Prinsip kerja dari sensor ini yaitu dengan cara mendeteksi perubahan konduktivitas gas di sekitar sensor. Perubahan konduktivitas ini direpresentasikan ke dalam perubahan resistansi keluaran sensor. Nilai resistansi tersebut kemudian perlu dihubungkan ke rangkaian pembagi tegangan agar didapatkan nilai perubahan tegangannya. Output sensor berupa nilai analog, sehingga diperlukan ADC untuk merubahnya ke dalam bentuk digital. Nilai digital ini yang akan diproses oleh mikrokontroller untuk mendapatkan nilai kadar ammonia dalam satuan part per million (ppm) (Budiman, Rivai \& Nugroho, 2019).

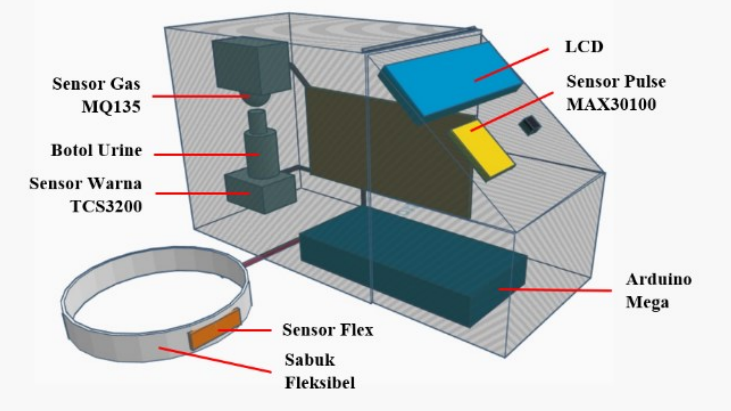

Gambar 2. Perancangan penempatan sensor
Seperti yang telah ditunjukkan pada Gambar 2, botol yang digunakan sebagai wadah urine merupakan botol tanpa tutup. Sensor gas diletakkan tepat di atas lubang botol tersebut, sehingga dapat melakukan pembacaan kadar ammonia secara langsung tanpa dipengaruhi oleh konduktivitas gas lain yang ada di luar botol. Dengan cara tersebut, diharapkan dapat memberikan pembacaan nilai ppm kadar ammonia secara akurat.

\subsection{Pendeteksian Denyut Jantung}

Denyut jantung pada penelitian ini dideteksi dengan menggunakan modul sensor MAX30100. Selain dapat digunakan untuk mengukur denyut jantung, sensor ini juga dapat digunakan untuk mengukur saturasi oksigen. Sensor MAX30100 menggunakan LED dan fotodetektor untuk mendeteksi perubahan volume darah yang mengalir pada jari. Dimana perubahan volume darah ini digunakan untuk menentukan denyut jantung. Terdapat dua buah LED pada modul sensor ini, satu LED memancarkan cahaya merah dan satu LED lagi memancarkan cahaya inframerah. Untuk mengukur denyut jantung, hanya LED pemancar inframerah yang diaktifkan. Cara kerja dari sensor ini adalah dengan memancarkan cahaya LED pada jari. Sebagian cahaya akan terserap oleh hemoglobin dan sebagian lagi akan direfleksikan kembali. Fotodetektor menangkap intensitas cahaya refleksi dan digunakan untuk perhitungan denyut jantung (Banuag \& Salva, 2019).

Seperti yang ditunjukkan pada Gambar 2, sensor MAX30100 diletakkan pada bagian luar boks. Pendeteksian denyut jantung dilakukan dengan cara menempelkan jari pada sensor tersebut selama 10 detik. Selama pengukuran berlangsung, posisi jari diharuskan stabil. Karena pergeseran pada jari dapat menyebabkan pendeteksian denyut jantung menjadi tidak akurat.

\subsection{Pendeteksian Laju Pernapasan}

Laju pernapasan pada penelitian ini diukur dengan menggunakan sensor flex. Sensor flex merupakan sebuah variabel resistor yang nilai resistansinya akan berubah ketika terjadi lekukan pada permukaannya. Agar perubahan nilai resistansi ini dapat diproses oleh mikrokontroller, maka diperlukan rangkaian pengkondisi sinyal yang terdiri dari rangkaian jembatan wheatstone dan rangkaian penguat differential. Rangkaian jembatan wheatstone berfungsi untuk mengkonversikan nilai resistansi menjadi nilai tegangan. Sedangkan rangkaian penguat differential berfungsi untuk memperkuat nilai tegangan keluaran jembatan wheatstone yang masih dalam orde milivolt (Roy et al., 2018). 
Seperti yang ditunjukkan pada Gambar 2, sensor flex ditempelkan pada sebuah sabuk karet yang nantinya digunakan melingkar pada perut. Laju pernapasan yang diukur pada penelitian ini adalah waktu yang dibutuhkan untuk satu siklus pernapasan, mulai dari menghirup hingga menghembuskan napas secara normal. Ketika menghirup napas, sensor flex akan melengkung karena bagian perut akan mengembang. Sehingga nilai resistansi dari sensor flex akan membesar. Peningkatan nilai resistansi dari sensor flex, digunakan sebagai pemicu untuk memulai perhitungan laju pernapasan. Ketika menghembuskan napas, sensor flex akan kembali ke bentuk awal dan nilai resistansinya menjadi kecil. Nilai terkecil dari pembacaan sensor flex digunakan sebagi pemicu untuk menghentikan perhitungan waktu laju pernapasan.

\subsection{Dataset}

Dataset yang digunakan dalam penelitian ini didapatkan dari salah satu rumah sakit yang ada di kota Malang. Dataset berupa data primer dari pasien penderita diare yang ada di rumah sakit tersebut. Masing-masing data sudah memiliki keterangan mengenai tingkatan dehidrasi yang dialami berdasarkan diagnosis dari dokter. Dataset yang digunakan berjumlah 75 data, dimana 50 data digunakan sebagai data latih dan 25 data digunakan sebagai data uji. Setiap data memiliki 6 fitur yang digunakan sebagai fitur klasifikasi, yaitu fitur RGB dari warna urine, kadar ammonia urine, denyut jantung dan laju pernapasan. Jumlah data untuk masing-masing tingkatan dehidrasi ditunjukkan pada Tabel 1.

\subsection{Klasifikasi Tingkat Dehidrasi Menggunakan Metode KNN}

Metode k-nearest neighbor $(\mathrm{KNN})$ merupakan sebuah metode yang melakukan klasifikasi berdasarkan mayoritas kelas yang muncul pada sejumlah $\mathrm{k}$ tetangga terdekat, dengan $\mathrm{k}$ merupakan jumlah tetangga terdekat yang digunakan. Tetangga merupakan data latih yang memiliki jarak paling dekat dengan data uji. Teknik pencarian jarak antara data latih dan dan data uji yang paling umum digunakan adalah euclidean distance (Singh \& Pandey, 2017). Persamaan (1) merupakan persamaan yang digunakan untuk menghitung euclidean distance. Pada Persamaan (1), $d$ merupakan euclidean

Tabel 1. Jumlah data untuk masing-masing tingkatan dehidrasi

\begin{tabular}{cc}
\hline tingkat dehidrasi & jumlah data \\
\hline ringan & 36 \\
sedang & 24 \\
berat & 15 \\
total & 75 \\
\hline
\end{tabular}

distance yang dihitung. Variabel $x$ adalah data uji dan $y$ adalah data latih. Sedangkan $n$ merupakan jumlah fitur dan $i$ adalah fitur ke- $n$.

$d=\sqrt{\sum_{i=1}^{n}\left(x_{i}-y_{i}\right)^{2}}$

Proses klasifikasi tingkat dehidrasi menggunakan KNN dijelaskan dalam diagram alir pada Gambar 3. Masukan yang digunakan oleh sistem adalah nilai fitur yang didapatkan dari akuisisi sensor warna, sensor gas, sensor denyut jantung dan sensor flex. Selain itu, karena metode KNN merupakan metode supervised learning, maka dibutuhkan data latih sebagai masukan dalam proses klasifikasi. Nilai $\mathrm{k}$ juga diperlukan sebagai masukan, sebagai penentu jumlah tetangga terdekat yang digunakan dalam metode KNN. Setelah diperoleh semua masukan yang dibutuhkan, langkah pertama yang dilakukan oleh sistem adalah melakukan normalisasi data semua fitur. Proses normalisasi diperlukan untuk menyeimbangkan jarak data semua fitur yang digunakan. Metode normalisasi min-max digunakan dalam penelitian ini. Hasil normalisasi akan menghasilkan nilai semua fitur berada di antara jarak 0 dan 1. Proses perhitungan normalisasi menggunakan metode min-max ditunjukkan pada Persamaan (2). Dimana $x_{\text {norm }}$ merupakan nilai yang sudah dinormalisasi. Sedangkan $x$ merupakan nilai sebelum dinormalisi, $x_{\min }$ adalah nilai terkecil dan $x_{\max }$ adalah nilai terbesar dari data yang digunakan.

$x_{\text {norm }}=\frac{x-x_{\min }}{x_{\max }-x_{\min }}$

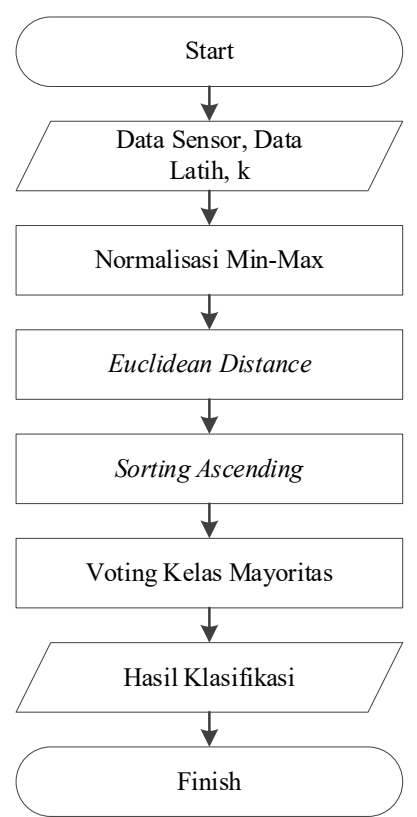

Gambar 3. Diagram alir sistem klasifikasi tingkat dehidrasi 
Setelah dilakukan normalisasi data, maka sistem akan melakukan proses klasifikasi menggunakan metode KNN. Langkah pertama dari metode KNN yaitu menghitung euclidean distance antara data uji dengan semua data latih. Hasil dari perhitungan euclidean distance kemudian diurutkan dari nilai terkecil hingga terbesar. Hasil klasifikasi ditentukan berdasarkan mayoritas kelas yang muncul dari sejumlah $\mathrm{k}$ tetangga terdekat. Terdapat tiga kelas pada penelitian ini, yaitu kelas dehidrasi ringan, sedang dan berat.

\section{HASIL DAN PEMBAHASAN}

Pada penelitian ini dilakukan pengujian untuk mengetahui tingkat akurasi sistem dalam mengklasifikasikan dehidrasi ringan, sedang dan berat. Pengujian dilakukan dengan membandingkan hasil klasifikasi metode KNN dengan status tingkat dehidrasi yang didapatkan dari diagnosis dokter.
Pengujian menggunakan 25 data uji yang terdiri dari 12 data dehidrasi ringan, 8 data dehidrasi sedang dan 5 data dehidrasi berat. Proses akuisisi data dari masing-masing sensor dapat dilihat pada Gambar 4. Gambar 4(a) merupakan proses akuisisi data warna dan kadar ammonia pada urine. Sedangkan Gambar 4(b) merupakan proses akuisisi data denyut jantung dan laju pernapasan.

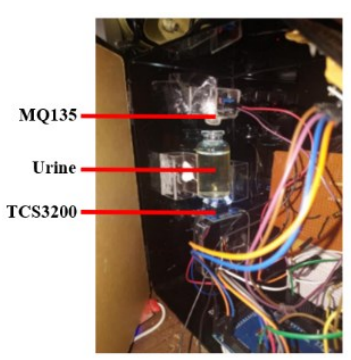

(a)

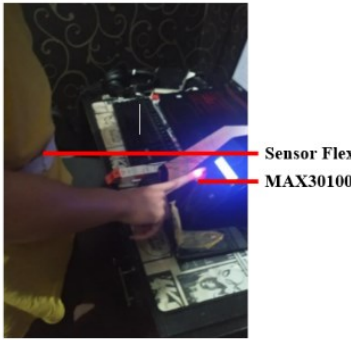

(b)
Gambar 4. Proses akuisisi data: (a) warna dan kadar ammonia pada urine; (b) denyut jantung dan laju pernapasan

Tabel 2. Perbandingan hasil klasifikasi sistem dengan diagnosis dokter

\begin{tabular}{|c|c|c|c|c|c|c|c|c|c|c|}
\hline \multirow{2}{*}{ data } & \multicolumn{3}{|c|}{ warna urine } & \multirow{2}{*}{$\begin{array}{c}\text { kadar } \\
\text { ammonia } \\
(p p m)\end{array}$} & \multirow{2}{*}{$\begin{array}{c}\text { denyut } \\
\text { jantung } \\
\text { (bpm) }\end{array}$} & \multirow{2}{*}{$\begin{array}{c}\text { laju } \\
\text { pernapasan } \\
\text { (s) }\end{array}$} & \multirow{2}{*}{$\begin{array}{c}\text { hasil } \\
\text { diagnosis } \\
\text { dokter }\end{array}$} & \multirow{2}{*}{$k=3$} & \multirow{2}{*}{$k=5$} & \multirow{2}{*}{$k=7$} \\
\hline & $\mathbf{R}$ & $\mathbf{G}$ & B & & & & & & & \\
\hline 1 & 185 & 174 & 68 & 0,17 & 73 & 4,97 & ringan & ringan & ringan & ringan \\
\hline 2 & 164 & 155 & 65 & 0,18 & 69 & 4,08 & ringan & ringan & ringan & ringan \\
\hline 3 & 145 & 117 & 36 & 0,19 & 85 & 4,19 & ringan & ringan & ringan & ringan \\
\hline 4 & 126 & 107 & 28 & 0,25 & 74 & 5,07 & ringan & ringan & ringan & ringan \\
\hline 5 & 150 & 144 & 36 & 0,16 & 88 & 4,33 & ringan & ringan & ringan & ringan \\
\hline 6 & 128 & 113 & 44 & 0,32 & 88 & 4,54 & ringan & ringan & ringan & ringan \\
\hline 7 & 120 & 90 & 65 & 0,06 & 95 & 2,92 & ringan & sedang & ringan & ringan \\
\hline 8 & 167 & 154 & 88 & 0,20 & 78 & 2,99 & ringan & ringan & ringan & ringan \\
\hline 9 & 143 & 128 & 84 & 0,12 & 74 & 2,57 & ringan & sedang & ringan & ringan \\
\hline 10 & 188 & 176 & 108 & 0,31 & 72 & 3,19 & ringan & ringan & ringan & ringan \\
\hline 11 & 148 & 141 & 90 & 0,16 & 65 & 3,05 & ringan & ringan & ringan & ringan \\
\hline 12 & 120 & 84 & 51 & 0,18 & 76 & 3,67 & ringan & ringan & ringan & ringan \\
\hline 13 & 129 & 96 & 40 & 0,12 & 88 & 2,72 & sedang & sedang & sedang & sedang \\
\hline 14 & 132 & 100 & 46 & 0,22 & 99 & 2,28 & sedang & sedang & sedang & sedang \\
\hline 15 & 135 & 100 & 46 & 0,20 & 93 & 2,19 & sedang & sedang & sedang & sedang \\
\hline 16 & 135 & 108 & 51 & 0,07 & 79 & 3,41 & sedang & ringan & ringan & ringan \\
\hline 17 & 132 & 92 & 40 & 0,07 & 83 & 1,73 & sedang & sedang & sedang & sedang \\
\hline 18 & 135 & 108 & 46 & 0,16 & 90 & 3,20 & sedang & sedang & sedang & sedang \\
\hline 19 & 135 & 100 & 46 & 0,09 & 89 & 3,69 & sedang & sedang & sedang & sedang \\
\hline 20 & 129 & 96 & 43 & 0,16 & 89 & 3,08 & sedang & sedang & sedang & sedang \\
\hline 21 & 141 & 112 & 58 & 0,06 & 105 & 1,92 & berat & berat & berat & berat \\
\hline 22 & 123 & 84 & 35 & 0,08 & 103 & 2,47 & berat & berat & berat & berat \\
\hline 23 & 141 & 108 & 55 & 0,10 & 101 & 2,27 & berat & berat & berat & berat \\
\hline 24 & 120 & 92 & 38 & 0,09 & 97 & 1,98 & berat & berat & berat & berat \\
\hline 25 & 144 & 120 & 60 & 1,06 & 87 & 2,18 & berat & berat & berat & berat \\
\hline
\end{tabular}


Pengujian akurasi KNN dilakukan dengan menggunakan tiga nilai $\mathrm{k}$ yang berbeda, yaitu $\mathrm{k}=3$, $\mathrm{k}=5$ dan $\mathrm{k}=7$. Penggunaan nilai $\mathrm{k}$ yang berbeda bertujuan untuk mengetahui nilai $\mathrm{k}$ yang paling optimal dalam proses klasifikasi tingkat dehidrasi. Hasil dari pengujian akurasi metode KNN ditunjukkan pada Tabel 2. Hasil tersebut digunakan untuk menentukan nilai akurasi sistem, yang didapatkan melalui perhitungan pada Persamaan (3). Dimana $a$ merupakan total data uji dan $b$ merupakan total data uji yang hasil klasifikasinya tidak tepat.

akurasi $=\frac{a-b}{a} \times 100 \%$

Dari hasil pengujian yang telah dilakukan, pada penggunaan nilai $\mathrm{k}=3$ terdapat 3 data yang hasil klasifikasinya berbeda dengan acuan diagnosis dokter. Sehingga akurasi sistem pada nilai $\mathrm{k}=3$ adalah $88 \%$. Sedangkan pada penggunaan nilai $\mathrm{k}=5$ dan $\mathrm{k}=7$ hanya terdapat 1 data yang hasil klasifikasinya tidak tepat. Sehingga pada kedua nilai $\mathrm{k}$ tersebut, didapatkan nilai akurasi sistem sebesar $96 \%$.

\section{KESIMPULAN}

Pada penelitian ini ditawarkan sebuah sistem untuk mendeteksi tingkat dehidrasi berdasarkan kondisi urine, denyut jantung dan laju pernapasan. Terdapat 6 fitur yang digunakan sebagai masukan sistem, yaitu fitur R,G dan B yang didapatkan dari pendeteksian warna urine, fitur kadar ammonia pada urine dalam satuan ppm, fitur denyut jantung dalam satuan bpm dan fitur laju pernapasan dalam satuan detik. Keenam fitur ini diproses menggunakan metode KNN untuk mendapatkan hasil klasifikasi berupa tingkatan dehidrasi yang dialami. Dimana terdapat tiga tingkatan dehidrasi, yaitu dehidrasi ringan, sedang dan berat. Terdapat 75 data yang digunakan dalam penelitian ini, dengan pembagian 50 data latih dan 25 data uji. Dari hasil pengujian yang dilakukan, metode KNN memiliki tingkat akurasi tertinggi sebesar 96\%. Dari hasil tersebut diketahui bahwa sistem yang dirancang mampu untuk mengklasifikasikan tingkatan dehidrasi dengan baik.

\section{DAFTAR PUSTAKA}

ANDREWS, J.R., LEUNG, D.T., AHMED, S., MALEK, M.A., AHMED, D., BEGUM, Y.A., QADRI, F., AHMED, T., FARUQUE, A.S.G. \& NELSON, E.J., 2017. Determinants of Severe Dehydration from Diarrheal Disease at Hospital Presentation: Evidence from 22 Years of Admissions in Bangladesh. PLOS Neglected Tropical Disease, vol. 11, pp. 1-16.

BALAMURUGAN, M., NANCY, A. \& VIJAYKUMAR, S., 2017. Alzheimer's Disease Diagnosis by Using Dimensionality Reduction Based on KNN Classifier.
Biomedical \& Pharmacology Journal, vol. 10, pp. 1823-1830.

BANUAG, L.C. \& SALVA, J.K.G., 2019. Development of a Patient Monitoring System for Hospital Wards Employing Zigbee Technology and CAN Protocol. World Symposium on Communication Engineering, pp. 112-116.

BUDIMAN, F., RIVAI, M. \& NUGROHO, M.A., 2019. Monitoring and Control System for Ammonia and $\mathrm{pH}$ Levels for Fish Cultivation Implemented on Raspberry $\mathrm{Pi}$ 3B. International Seminar on Intelligent Technology and Its Application, pp. 68-73.

FUKUSHIMA, Y., SANO, Y., ISOZAKI, Y., ENDO, M., TOMODA, T., KITAMURA, T., SATO, T., KAMIJO, Y., HAGA, Y. \& YODA, T., 2018. A Pilot Clinical Evaluation of Oral Mucosal Dryness in Dehydrated Patients using a MoistureChecking Device. Clinical and Experimental Dental Research, vol. 5, pp. 116-120.

GUNAWAN, A.A.S., BRANDON, D., PUSPA, V.D. \& WIWEKO, B., 2018. Development of Urine Hydration System Based on Urine Color and Support Vector Machine. International Conference on Computer Science and Computational Intelligence, $\mathrm{pp}$. 481-489.

KIM, K.B. \& KWAK, Y.S., 2019. Dehydration Affects Exercise-Induced Asthma and Anaphylaxis. Journal of Exercise Rehabilitation, vol. 15, pp. 647-650.

KOLEVA, G., 2019. Dehydration at Seafarers Prevention, Symptoms and Approaches. Scientific Bulletin of Naval Academy, vol. 22, pp. 78-82.

MAULANA, R., SYAUQY, D. \& AMANI, R.Z., 2017. Dehydration Level Detection System Based on Urine Condition. International Conference on Signal Processing Systems, pp. 207-210.

PANIE, G.I.E. \& MUTIARA, A.B., 2018. Development of Robotic Arm for Color Based Goods Sorten in Factory Using TCS3200 Sensor with a Web-Based Monitoring System. International Conference on Informatics and Computing, pp. 1-6.

ROY, R.K., HAZARIKA, N., SINGH, H.K. \& BEZBORUAH, T., 2018. A Novel Method for Measurement of Linear Displacement by Using Extension Spring and Flex Sensor. International Conference on Power, Energy and Environment: Towards Smart Technology, pp. 1-9. 
SEVEREYN, E., VELASQUEZ, J., PERPINAN, G., HERRERA, H., PACHECO, M. \& WONG, S., 2016. Heart Rate Variability Analysis During a Dehydration Protocol on Athletes. Symposium on Signal Processing, Images and Artificial Vision, pp. 1-7.

SHAHEEN, N.A., ALQAHTANI, A.A., ASSIRI, H., ALKHODAIR, R. \& HUSSEIN, M.A., 2018. Public Knowledge of Dehydration and Fluid Intake Practices: Variation by Participants Characteristics. BMC Public Health, vol. 18, pp. 1346.

SINGH, A. \& PANDEY, B., 2017. An Euclidean Distance Based KNN Computational Method for Assessing Degree of Liver Damage. International Conference on Inventive Computation Technologies, pp. 14.

WILLIHNGANZ, M.J., GUREVITZ, S.L. \& CLAYTON, B.D., 2020. Clayton's Basic Pharmacology for Nurses. St. Louis: Elsevier. 
Halaman ini sengaja dikosongkan 